Vol.2 No.2 Hal. $17-23$

September 2019

\title{
Pengaruh Iklim Organisasi Terhadap Kepuasan Kerja Pada PT Telkom Akses Medan
}

\author{
Adrial Falahi \\ Universitas Muslim Nusantara Al-Wasliyah Medan \\ Adrial.falahi@gmail.com
}

\begin{abstract}
ABSTRAK
Keberhasilan perusahaan/organisasi dalam mencapai tujuannya tidak terlepas dari berbagai hal, salah satu diantaranya adalah peran dari iklim organisasi. Iklim organisasi ini akan memberikan dampak yang cukup besar terhadap kepuasan kerja berupa semangat dan kemauan kerja yang akan berujung kepada peningkatan disiplin kerja dan pencapaian tujuan perusahaan/organisasi. Tujuan penelitian ini untuk mengetahui dan menganalisis pengaruh iklim organisasi terhadap kepuasan kerja pada PT. Telkom Akses Medan. Penelitian ini menggunakan metode penelitian kuantitatif dengan pengambilan sampel menggunakan simple random sampling berjumlah 39 orang. Teknik pengumpulan data menggunakan kuesioner dengan penilaian memakai Skala Likert. Hasil penelitian menunjukkan bahwa ada pengaruh yang positif serta signifikan antara iklim organisasi dengan kepuasan kerja karyawan. Hasil penelitian ini juga menunjukkan bahwa hubungan antara kedua variabel berbanding lurus yang berarti bahwa semakin baik iklim organisasi yang diterapkan di perusahaan/organisasi, maka akan semakin baik pula tingkat kepuasan kerja karyawan. Diharapkan dengan penelitian ini maka perusahaan akan dapat terus menciptakan serta menjaga iklim organisasi yang baik serta mendukungnya sehingga akan dapat memberikan kepuasan kerja bagi karyawan yang akan berakibat kepada pencapaian tujuan dari perusahaan/organisasi.
\end{abstract}

Kata Kunci : Iklim Organisasi, Kepuasan Kerja

\begin{abstract}
The success of the company / organization in achieving its goals is inseparable from various things, one of which is the role of the organizational climate. This organizational climate will have a significant impact on job satisfaction in the form of enthusiasm and willingness to work which will lead to an increase in work discipline and the achievement of company / organizational goals. The purpose of this study was to determine and analyze the effect of organizational climate on job satisfaction at PT. Telkom Access Medan. This study uses quantitative research methods by sampling using simple random sampling totaling 39 people. Data collection techniques using a questionnaire with an assessment using a Likert Scale. The results showed that there was a positive and significant effect between organizational climate and employee job satisfaction. The results of this study also show that the relationship between the two variables is directly proportional, which means that the better the organizational climate applied in the company / organization, the better the level of employee job satisfaction. It is expected that with this research the company will be able to continue creating and maintaining a good organizational climate and supporting it so that it will be able to provide job satisfaction for employees which will result in achieving the goals of the company / organization.
\end{abstract}

Keywords : Organizational Climate, Job Satisfaction 


\section{PENDAHULUAN}

\section{Latar Belakang}

Organisasi adalah sarana atau alat atau wadah untuk mencapai suatu tujuan. Di dalam organisasi manusia (SDM) merupakan salah unsur terpenting di dalam pencapaian suatu tujuan. Tanpa peran manusia meskipun sebagai faktor yang dibutuhkan telah tersedia, organisasi tidak akan berjalan. Seiring dengan perkembangan IPTEK menyebabkan terjadinya perubahan sikap, prilaku, dan pola pikir, cara pandang manusia atas hal atau peristiwa yang ada disekitarnya. Hal ini kemudian berdampak kepada berariasinya kepuasan kerja pada setiap kegiatan operasional sebuah organisasi. Kepuasan kerja mencerminkan perasaan seseorang terhadap pekerjaannya yang dapat dilihat dari sikap positif individu terhadap pekerjaan dan segala sesuatu yang dihadapi dilingkungan kerjanya. Untuk menciptakan kepuasan kerja, Iklim organisasi dianggap menjadi salah satu faktor yang berperan penting iklim organisasi yang terbentuk akan mempengaruhi prilaku karyawan dalam bekerja, yang selanjtnya akan berpengaruh pada hasil kerja. Iklim organisasi yang baik akan memberikan kepuasan kerja yang baik yang apda akhirnya akan berpengaruh kepada peningkatan kinerja baik secara individu ataupun organisasional. Sebaliknya iklim organisasi yang kurang kondusif akan menyebabkan suasana kerja yang tidak nyaman dengan masih banyaknya keadaan ruangan yang tidak mendukung kinerja para karyawan dan berdampak pada kepuasan kerja karyawan yang rendah. Perbedaan iklim organisasi yang terjadi antara satu bidang dengan bidang lainnya dapat dilihat misalnya pada situasi ruangan kerja secara fisik yang tidak mendukung dimana karyawan membutuhkan fasilitas yang memadai seperti suasana ruangan yang tenang dan nyaman tetapi kenyataannya tidak sehingga menimbulkan rasa ketidaknyamanan dan kurangnya inisiatif karyawan terhadap pekerjaan yang dijalaninya.

\section{Perumusan Masalah}

Sebagai salah satu perusahaan informasi dan komunikasi serta penyedia jasa dan jaringan telekomunikasi secara lengkap di Indonesia. Telkom mengklaim sebagai perusahaan telekomunikasi terbesar di indonesia. PT Telkom Akses (PPTA) merupakan anak perusahaan PT Telekomunikasi Indonesia, Tbk (Telkom) yang sahamnya dimiliki sepenuhnya oleh telkom (PTTA) bergerak dalam bisnis penyediaan layanan konstruksi dan pengelolaan infrastruktur jaringan.

\section{Tujuan Penelitian}

Tujuan penelitian ini adalah untuk mengetahui bgaimana pengaruh iklim organisasi terhadap kepuasan kerja pada PTTelkom Akses Medan.

\section{Manfaat Penelitian}

1. Dapat menjadi input bagi pengembangan ilmu MSDM.

2. Dapat menjadi input bagi karyawan dalam rangka peningkatkan kepuasan kerja dan secara jangka panjang dapat meningkatkan kinerjanya.

3. Dapat m,enjadi input bagi masyarakat umum terutama dalamhal peningkatan kualitas SDM dalam menyikapi persaingan global.

\section{Kajian Literatur}

Penelitian ini dianggap penting karena sehaik apapun sumber daya yang ada dan dimiliki sebuah perusahaan peranan manusia adalah yang paling utama untuk diperhatikan. Dengan kata lain sumber daya yang berlimpah yang dimiliki sebuah perusahaan akan sia-sia jika dikelola orang-orang yang tidak mempunyai kepuasan kerja yang tinggi dan akan perilaku kerja yang tidak baik. Melihat fenomena ini maka penulis menganggap bahwa sebuah 
perhatian terhadap iklim kerja akan berdampak kepada kepuasan kerja yang selanjutyna akan mempengaruhi kinerjanya.

\section{METODE PENELITIAN Desain Penelitian}

Agar pelaksanaan penelitian berjalan dengan baik maka penulis memilih suatu metode penelitian yang bersifat deskriptif kuantitatif. Alat pengumpul atau instrument penelitian yang dgunakan adalah angket (kuesioner). Data diukur dengan skala Likert dan selanjutnya dilakuan berbagai tahapan uji. Tahapan tersebut adalah uji validitas, uji reabilitas, uji asumsi klasik, uji regresi sederhana ujit t dan uji korelasi.

\section{Populasi dan Sampel}

Populasi dalam penelitian ini adalah karyawan tetap yang bekerja di PT Telkom Akses Medan yang berjumlah 39 karyawan. Teknik penentuan sampel yang dipakai adalah sampel jenuh. Maka jumlah sampel yang ditetapkan sama dengan jumlah populasinya.

\section{Tempat, Waktu Dan Waktu Penelitian}

Penelitian ini dilakukan di PT. Telkom Akses Jln. Gaharu No. 1 Gaharu. Waktu penelitian dilaksanakan mulai dari bulan Maret s/d Mei 2019. Penelitian dirancang \pm selama 3 (tiga) bulan. Satu bulan pertama untuk mengurus perizinan, uji coba instrumen dan revisi. Dua bulan berikutnya untuk pengumpulan dan analisis data dan untuk bulan ketiga penyusunan laporan hasil penelitian

\section{Definisi Operasional dan Indikator Iklim Organisasi}

Iklim organisas adalah suatu konsep yang melukiskan sifat subjektif atau kualitas lingkungan sebuah organisasi. Indikator penelitian mengacu kepada pendapat Luthan.yang terdiri dari : 1). Pekerjaan Itu Sendiri, 2). Gaji, 3). Kondisi Kerja, 4). Promosi, 5). Pengawasan, 6). Rekan Kerja

\section{Jenis Data dan Sumber Data}

Teknik pengumpulan data yang digunakan adalah kuesioner, wawancara dan studi kepustakaan. Data yang digunakan terdiri dari dua jenis yaitu data primer dan data sekunder. Data primer adalah data yang didapat dari sumber pertama (sumber asli) yang biasanya diperoleh langsung dari responden melalui kuesioner Data sekunder yaitu data yang diambil dan diperoleh dari sumber kedua atau bukan dari sumber aslinya seperti melalui studi kepustakaan dengan membaca buku-buku, media cetak, jurnal, internet dan lainnya yang berhubungan dengan penelitian ini.

\section{Teknik Analisis Data}

Dalam melakukan kegiatan penelitian ini tehnik pengumpulan data yang digunakan penulis adalah sebagai berikut :

1. Observasi,

Observasi adalah pengumpulan data yang dilakukan dengan proses pengamatan data yang terlebih dahulu melakukan pengamatan langsung kelokasi penelitian. Pengamatan ini merupakan salah satu untuk mendapatkan data yang relavan dengan masalah yang akan diteliti, dalam hal ini dilakukan pada PT.Telkom Akses.

2. Kuesioner (Angket)

Kuesioner yaitu teknik pengumpulan data dengan cara menyiapkan satu set peryataan yang tersusun secara sistematis dan standar yang diberikan kepada responden untuk dijawab tentang variabel iklim organisasi (X) dan kepuasan kerja (Y), kemudian dari jawaban itu diberikan skornya dengan skala Likert. Sakala likert mempunyai interval 15 , untuk jawaban yang mendukung pertayaan atau peryataan diberi skor terendah. 


\section{Uji Validitas dan Reliabilitas}

Uji validitas dilakukan untuk mengtahui sejauh mana ketepatan dan kecermatan suatu alat ukur (instrumen penelitian) mampu melakukan fungsi ukurnya. Untuk menguji validitas data dapat dilakukan dengan memban-dingkan $\boldsymbol{r}$ hitumg (Corrected Item-Total Correlation) dengan $\boldsymbol{r}$ table. Jika $r_{\text {hitung }}>r$ tabel maka suatu item butir soal dapat dinyatakan valid. Riduwan (2010: 353) menjelaskan, Corrected Item-Total Correlation merupakan korelasi antara skor item dengan skor total item ( $\mathrm{r}$ hitung) dibandingkan dengan $\mathrm{r}_{\text {tabel }}(a l f a=0,05)$. Jika $\boldsymbol{r}_{\text {hitung }}>\boldsymbol{r}$ tabel maka item tersebut dinyatakan valid. Uji reliabilitas bertujuan untuk mengetahui tingkat kestabilan suatu alat ukur (instrument). Reliabilitas suatu hasil ukur dapat dilakukan dengan melihat nilai Cronbach Alpha (secara umum nilainya adalah >0.7). Uji reliabilitas dalam penelitian ini menggunakan Cronbach Alpha yang dapat dililihat pada Output SPSS Item Total Statistic. Kriteria reabilitias adalah sebagai berikut:

1. Jika $\mathbf{r}$ alpha positif atau $>\mathbf{r}$ tabel, maka pernyataan dikatakan reliabel.

2. Jika $\mathbf{r}$ alpha negatif atau $<\mathbf{r}$ tabel, maka pernyataan dikatakan tidak reliabel.

3. Jika ralpha $>0,7=$ sangat kuat, jika $0,5 \geq$ ralpha $\leq 0,7=$ kuat, jika $0,5<$ ralpha $>0=$ sedang, dan jika ralpha $\leq 0=$ lemah.

4. Kriteria umum terhadap reliabilitas adalah jika koefisien ralpha $(\alpha)$ Cronbach's $>0.70$ artinya data yang diperoleh melalui kuesioner hasilnya konsisten bila digunakan untuk penelitian yang lain

\section{Uji asumsi klasik}

Untuk mendapatkan hasil penelitian yang baik dalam model regresi harus dilakukan uji asumsi klasik. Uji asumsi klasik yang harus dipenuhi dalam sebuah model regresi sederhana antara lain adalah sebagai berikut :

\section{Uji normalitas.}

Uji normalitas dilakukan untuk memastikan apakah model regresi yang dipilih memiliki data yang telah terdistribusi secara normal atau tidak normal(outlier). Normalitas dapat dili-hat pada output SPSS grafik Histogram dan Normal P-P Plot of Regres-sion Standardized Residual. Grafik ini akan menunjukkan apakah penyebaran titik berada di sekitas garis diagonal dan mengikuti arah garis diagonal.

\section{Uji heterokedastisitas.}

Model regresi yang baik adalah homoskedastisitas atau tidak terjadi heterokedastisitas. Salah satu cara untuk melihat terjadi tidaknya heteroskedastisitas dapat dilihat pada chart/grafik Scatterplot (pola sebaran) dengan menganalisa apakah titik-titik (pola) menyebar di atas atau dibawah angka 0 pada sumbu Y (vertikal).

\section{Analisis data}

Teknik analisis data yang digunakan ini adalah model regresi linier sederhana. Untuk menjawab hipotesis, dianalisa dengan uji t dan uji koefisien determinasi (uji R) dengan bantuan computer statistic software - SPSS 20.00.

\section{Analisa Regresi}

Riduan dan Sunarto (2009: 108) menjelaskan, pengaruh $X$ terhadap $Y$ dapat dirumuskan dalam sebuah persamaan yaitu :

$$
Y=a+b x
$$

\section{Uji t}

Riduwan dan Sunarto (2009: 341) mengatakan. apabila nilai signifikan lebih kecil dari derajat kepercayaan maka Ho ditolak dan Ha diterima. Analisis uji t dapat dilihat pada output SPSS dari tabel "Coefficient(a)" dengan kriteria t hitung harus $>$ dari t tabel. 
Uji Koefisien Determinasi (uji $R$ ).

Uji $\boldsymbol{R}^{2}$ dapat dijelaskan dengan menganalisa nilai $(\boldsymbol{R})$ yang secara umum berkisar antara $\mathbf{0}$ 1. Jika hasilnya mendekati angka 0 berarti kemampuan variabel bebas menjelaskan variabel terikat sangat terbatas.Untuk analisisnya dapat dilihat pada output SPSS tabel "Model Summary" kolom R. Square.

\section{HASIL DAN PEMBAHASAN}

Uji Validitas dan Uji Reliabilitas

Dari 5 responden yang dijadikan sampel uji memberikan jawaban yang valid sesuai dengan tabel berikut ini :

\section{Hasil Uji Validitas}

\begin{tabular}{|c|c|c|c|c|}
\hline \multicolumn{5}{|c|}{ Item-Total Statistics } \\
\hline & $\begin{array}{l}\text { Scale Mean if } \\
\text { Item Deleted }\end{array}$ & $\begin{array}{l}\text { Scale Variance } \\
\text { if Item Deleted }\end{array}$ & $\begin{array}{l}\text { Corrected Item- } \\
\text { Total Correlation }\end{array}$ & $\begin{array}{l}\text { Cronbach's } \\
\text { Alpha if Item } \\
\text { Deleted }\end{array}$ \\
\hline $\mathrm{X} 1.1$ & 74.59 & 50.459 & .669 & .959 \\
\hline $\mathrm{X} 1.2$ & 74.64 & 49.499 & .835 & .957 \\
\hline $\mathrm{X} 1.3$ & 74.72 & 49.787 & .542 & .961 \\
\hline $\mathrm{X} 1.4$ & 74.69 & 48.587 & .881 & .956 \\
\hline $\mathrm{X} 1.5$ & 74.72 & 50.471 & .637 & .959 \\
\hline $\mathrm{Y}_{1}$ & 74.74 & 49.459 & .764 & .958 \\
\hline $\mathrm{Y}_{2}$ & 74.72 & 48.576 & .841 & .957 \\
\hline $\mathrm{Y}_{3}$ & 74.72 & 48.682 & .825 & .957 \\
\hline $\mathrm{Y}_{4}$ & 74.69 & 50.534 & .667 & .959 \\
\hline $\mathrm{Y}_{5}$ & 74.72 & 48.366 & .787 & .958 \\
\hline
\end{tabular}

Dari tabel diatas, dapat diketahui bahwa masing-masing pertanyaan bernilai positif lebih besar dari pada 0.325 . Sehingga seluruh item pertanyaan layak dijadikan sebagaialatukur dalampenelitian ini.

Uji reliabilitas dilakukan dengan teknik cronbach' alpha dengan hasil seperti pada tabel berikut ini :

\section{Reliability Statistics}

\begin{tabular}{|l|l|}
\hline Cronbach's Alpha & N of Items \\
\hline .960 & 20 \\
\hline
\end{tabular}

Berdasarkan hasil tersebut dapat diketahui nilai reliabilitas adalah tinggi yaitu semakin mendekati 1. Maka instrument penelitian semakin baik. Nilai reliabilitas instrument diatas menunjukan tingkat realibilitas instrument penelitian sudah memadai karena sudah mendekati 1.

\section{Uji Asumsi Klasik}

\section{Uji Normalitas}

Uji normalitas bertujuan untuk mengetahui apakah variabel dependen dan independen yang digunakan dalam penelitian mempunyai distribusi normal atau tidak. Model regresi yang layak mempunyai distribusi normal atau mendekati normal. Hasil pengujian dapat dilihat melalui grafik histogram sebagai berikut: 


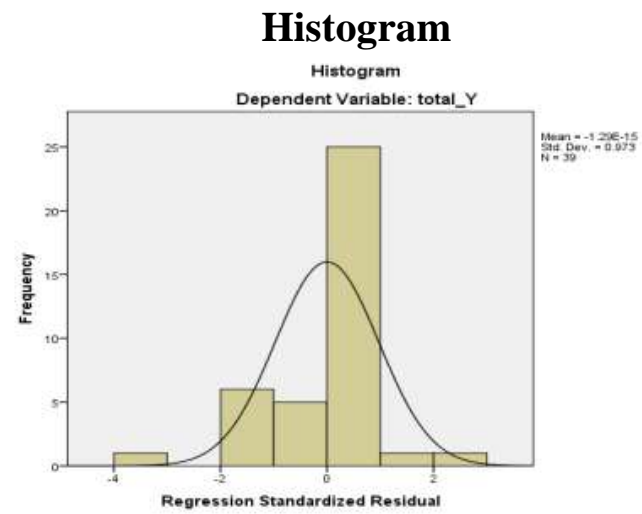

Hasil uji melalui grafik histogram pada gambar memperlihatkan bahwa distribusi data mengikuti kurva berbentuk lonceng yang tidak menceng (skewness) ke kiri maupun ke kanan atau dapat disimpulkan bahwa data terdistribusi normal.

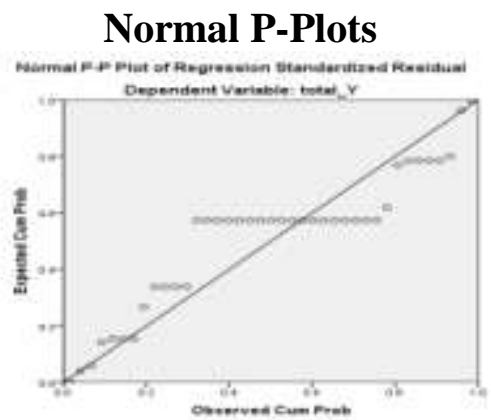

Hasil uji normalitas P-Plot pada gambar menunjukan bahwa titik-titik menyebar disekitar garis diagonal serta penyebarannya mengikuti garis diagonal sehingga dapat disimpulkan bahwa data dalam model regresi distribusi normal.

\section{Uji Heterokedastisitas}

Uji ini dilakukan untuk mengetahui apakah disebuah model regresi terjadi ketidaksamaan varians dari residual dari suatu pengamatan lain. Heterokedastisitas dapat dilihat melalui grafik Scatterplot berikut ini:

\section{Heterokedastisitas}

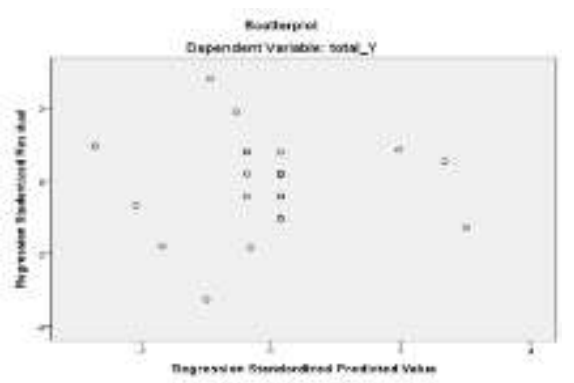

Pada gambar grafik Scatterplot diatas terlihat bahwa titik-titik menyebar secara acak diatas dan di bawah angka 0 pada Y, serta tidak membentuk pola tertentu atau tidak teratur hal ini mengindikasikan tidak terjadi heteroskedastisitas pada model regresi sehingga model regresi layak dipakai. 


\section{KESIMPULAN}

Hasil uji regresi mengasilkan sebuah persamaan regresi linier sederhana yaitu $\mathrm{Y}=11.475+$ 1.419 X. Hasil uji $\boldsymbol{t}$ menyatakan bahwa iklim organisasi terbukti berpengaruh positif dan signifikan terhadap kepuasan kerja di PT TELKOM AKSES MEDAN (Ha terbukti). Berdasarkan analisa korelasi (Uji R) iklim organiasi mempunyai tingkat hubungan yang sangat tinggi dengan kepuasan kerja. Sehingga variabel ini dapat dijadikan sebagai kekuatan dalam hal menyusun dan menetapkan strategi bisnis yang lebih tepat masa kini dan masa yang akan datang.

\section{DAFTAR PUSTAKA}

Luthans 2015. Prilaku Organisasi. Edisi Kesepuluh. Indonesia. Andi Publisher.

Mangkunegara, 2013. Manajemen Sumber Daya Manusia Perusahaan, Remaja Rosdakarya, Bandung.

Rianse, dan Abdi, 2009. Metode Penelitian Sosial dan Ekonomi, Cetakan II. Bandung: Alpabeta.

Riduan, 2010. Skala Pengukuran Variabel-variabel Penelitian. Cetakan VII, Bandung: Alfabeta.

Stephen. 2008. Prilaku Organisasi. Jakarta. PT.Indeks.Kelompok Gramedia.

Stringer dan Judge. (2012). Prilaku Organisasi. Cetakan 12 Jakarta.Salemba Empat.

Sugiyono. Metode Penelitian Kuantitatif, Kualitatif, dan R\&D.Cetakan Ke- 20 Mei 2018. Bandung .Alfabeta.

Wibowo. Manajemen Kinerja. Cetakan Ke Empat. Jakarta. Rajawali Pers. 2014.

Wirawan (2016).Budaya Dan Iklim Organisai.Cetakan Kedua.Jakarta. Salemba Empat. 